\title{
ANÁLISE DA DISPERSÃO LARVAL DE PANULIRUS SP. POR MODELAGEM NUMÉRICA: A INFLUÊNCIA DA PLUMA DO AMAZONAS E DAS CORRENTES NA CONECTIVIDADE ECOLÓGICA ENTRE A MARGEM EQUATORIAL BRASILEIRA E O CARIBE
}

\author{
Cordeiro, V.P.N. ${ }^{1}$; Bezerra, L.E.A. ${ }^{1}$; Cruz, R. $^{1}$ \& Teixeira, C.E.P. ${ }^{1}$ \\ ${ }^{1}$ Instituto de Ciências do Mar (LABOMAR), \\ Laboratório de Invertebrados Bentônicos (ZOOBENTOS) - Fortaleza, Ceará, Brasil. \\ *Autor correspondente: ocecept@gmail.com
}

\begin{abstract}
As lagostas espinhosas (Panulirus spp.) são organismos meroplanctônicos amplamente distribuídos e que ocupam lugar de destaque na economia pesqueira do Atlântico Tropical. No entanto, as características da sua dispersão larval a longas distâncias são pouco conhecidas. A Duração Pelágica larval desses organismos é tipicamente longa, o que os permite migrar longas distâncias através das correntes oceânicas. Neste trabalho foi testada a conectividade ecológica entre a Plataforma Continental Norte Nordeste do Brasil (PCNNB) e o Caribe e a atuação das baixas salinidades desenvolvidas pela pluma do Amazonas como barreira para o transporte dessas larvas entre essas duas regiões. Para tanto foram analisadas as trajetórias de boias de deriva e modelagem numérica. Com base em um modelo de dispersão larval baseado no individuo foram gerados três cenários com salinidades letal de 32, 33 e 34. As simulações foram feitas com base na circulação e salinidades provenientes do modelo global Mercartor para os anos de 2009 e 2016, extremos de baixa e alta salinidade na região de estudo. Nestas simulações, o modelo foi configurado de forma as larvas se deslocarem livremente na vertical entre 0 e $100 \mathrm{~m}$. Os resultados indicam a existência de conectividade física entre as regiões dentro do período de duração pelágica larval da lagosta espinhosa Panulirus spp. A conexão ocorre preferencialmente entre 90 e 120 dias com o deslocamento ao longo da margem Equatorial Brasileira, porém as larvas podem chegar a região do Caribe com apenas 56 dias. A salinidade foi capaz de reduzir a conectividade entre as regiões, mas não bloqueá-la por completo. As simulações com maiores salinidades letais promoveram maior redução da conexão. Aproximadamente 1\%, 3.5\% e $6 \%$ das larvas liberadas chegam ao Caribe para salinidades letais de 34, 33 e 32, respectivamente. Houve pouca diferença interanual tanto para a conectividade quanto para a atuação da pluma dos Rios Amazonas e Orinoco como barreira. As profundidades de deslocamento das larvas se mostraram determinantes na mortalidade das mesmas devido a salinidade. Nas simulações com as larvas fixas em determinadas profundidades as maiores taxas de mortalidade ocorrem em menores profundidades. Assim, conclui-se que existe conectividade entre a PCNNB e o Caribe, especialmente entre outubro e janeiro, e que a pluma do Amazonas não é uma barreira física para a dispersão, embora atue reduzindo consideravelmente o número de larvas que chegam à região do Caribe.
\end{abstract}

Palavras-chave: Panulirus, barreira do Amazonas, dispersão larval, modelagem numérica. 